\title{
Parentage testing and effect of misidentification on the estimation of breeding value in Gir cattle
}

\author{
Erica E. Baron ${ }^{1}$, Mário L. Martinez ${ }^{2}$, Rui S. Verneque ${ }^{2}$ and Luiz L. Coutinho ${ }^{1}$ \\ ${ }^{1}$ Department of Animal Production, Escola Superior de Agricultura “Luiz de Queiroz” - ESALQ, USP. \\ ${ }^{2}$ Empresa Brasileira de Pesquisa Agropecuária - Embrapa, Centro Nacional de Pesquisa de Gado de Leite.
}

\begin{abstract}
A correct relationship among sires is essential for an efficient breeding program. Microsatellite markers were used in progeny tests, to assess the paternity of seventy-four probable offspring of nine Gir dairy sires. A $36 \%$ misidentification rate was observed; however, these errors had minimal effects on the ranking of the nine bulls with regard to their genetic values. The results suggest that paternity tests should be performed in breeding programs, in order to prevent inappropriate paternities from influencing the genetic value of bulls in the future.
\end{abstract}

Key words: microsatellite, Gir, cattle, breeding, parentage, PCR.

Received: May 29, 2000; accepted: August 7, 2002.

\section{Introduction}

Breeding programs have been of considerable importance to improve productivity in the animal industry. In dairy cattle, progeny testing is the method of choice; however, this method presents two drawbacks limiting its use: 1) high cost, and 2) increased generation intervals. These obstacles can be overcome when large numbers of progenies are obtained by artificial insemination. Therefore, accurate parentage information is of critical importance for the estimation of the genetic values of the animals.

Different types of markers have been used in paternity testing. In recent years, microsatellite markers have been used, because of their large polymorphism information content, widespread distribution in the genome, the type of samples that can be used (e.g., blood and hair), the possibility to process several samples at the same time, and the fact that the results are easy to interpret. Many microsatellites have been described in bovine genomes (Barendse et al., 1994; Moore et al., 1994; Vaiman et al., 1994; Burns et al., 1995, Glowatzki-Mulis et al., 1995; Stone et al., 1995; Usha et al., 1995; Heyen et al., 1997; Kappes et al., 1997) and, due to their high polymorphism, they have been proposed as relationship verification markers for bovine herds. Usha (1995) and Heyen (1997) suggested using at least five microsatellite markers in the same analysis to achieve a 0.99 probability of exclusion of an incorrect sire.

Send correspondence to L.L.Coutinho. Departamento de Produção Animal, ESALQ-USP, Av. Padua Dias, 11, 13418-900 Piracicaba, SP, Brazil. E-mail: Ilcoutin @ carpa.ciagri.usp.br.
The purpose of this study was to verify the paternity of Gir bulls participating of a progeny test, and to calculate the misidentification rate and its effect on genetic value estimation, using microsatellite markers.

\section{Material and Methods}

\section{Animals}

Nine bulls and 74 progenies (six to nine per sire) from 15 different herds participanting of a Gir dairy cattle progeny test were used.

\section{DNA extraction}

Two protocols were used for blood samples: the standard protocol for "FTA cards" and "Gene cards" (GIBCO BRL - Life Technologies), and the protocol for Chelex-100 (Bio-Rad). For the first one, we used a $2 \mathrm{~mm}$ punch to remove samples from the FTA cards for blood collection. The samples were placed in an amplification tube of at least $300 \mu \mathrm{L}$. Three times $200 \mu \mathrm{L}$ of FTA purification reagent (GIBCO - Life Technologies) each were added to each tube, with a five-minute interval between washings. Then, $200 \mu \mathrm{L}$ of modified TE solution (10 mM Tris-HCL pH 8.0 and $0.1 \mathrm{mM}$ EDTA) were added, and the paper washed twice, with a 5 min interval between washings. The paper was then completely dried for one hour at room temperature, or for $30 \mathrm{~min}$ at $60{ }^{\circ} \mathrm{C}$. Finally, PCR (polymerase chain reaction) solution was added to the tubes to a final volume of $40 \mu \mathrm{L}$. 
For the Chelex-100 protocol (Walsh et al., 1991), $6 \mathrm{~mm}$ of the FTA cards were cut out, placed in $1 \mathrm{~mL}$ water, and left at room temperature for $30 \mathrm{~min}$. Samples were then centrifuged at 10,000 rpm for 5 minutes. The supernatant was removed, and $200 \mu \mathrm{L} 5 \%$ Chelex were added. The tubes were incubated at $56{ }^{\circ} \mathrm{C}$ for $35 \mathrm{~min}$. After being vortexed at high speed for 5-10 s, the samples were boiled for $8 \mathrm{~min}$ and separated in aliquots.

DNA was extracted from semen samples using proteinase $\mathrm{k}$, according to the protocol used by Shuster (1992), followed by a CTAB (hexadecyltrimethylammonium bromide) cleaning method described by Via (1993).

\section{$\mathrm{PCR}$ reaction}

\section{Blood}

Amplification reactions were prepared for a final volume of $40 \mu \mathrm{L}$. The PCR protocol for five of the six microsatellites (BM8246, BMS963, BMS483, INRA112, and TEXAN15) was as follows: $5.0 \mu \mathrm{L} 10 \mathrm{X}$ PCR buffer; $3.0 \mu \mathrm{M} \mathrm{MgCl} \mathrm{Mg}_{2} ; 0.2 \mu \mathrm{M}$ forward primer; $0.2 \mu \mathrm{M}$ reverse primer; $2 \mathrm{~mm}$ "FTA card" or "Gene card"; $0.25 \mu \mathrm{M}$ dNTP; 2 units of Taq DNA polymerase. For microsatellite CSFM50, the conditions were different regarding primer concentration, which was $0.01 \mu \mathrm{m}$ for both primers. Forty amplification cycles were performed.

The steps used for PCR amplifications were: initial DNA denaturation at $96{ }^{\circ} \mathrm{C}$ for $5 \mathrm{~min}$; 40 denaturation cycles at $94{ }^{\circ} \mathrm{C}$ for $2 \mathrm{~min}$, annealing at primer-specific temperature (Table I) for $30 \mathrm{~s}$, extension at $72^{\circ} \mathrm{C}$ for $30 \mathrm{~s}$, and a final extension at $72{ }^{\circ} \mathrm{C}$ for $4 \mathrm{~min}$.

Table I shows the primer sequences of the six microsatellites, as well as their annealing temperatures.

\section{Semen}

Each $200 \mu \mathrm{L}$ sample of semen DNA was divided into $5 \mu \mathrm{L}$ aliquots for PCR analysis. Thermocycle programs for all six microsatellites were the same as those used to amplify the blood samples, including the number of cycles in the "PTC-100 Programmable Thermal Controller" (M.J. Research) and the "GeneAmp PCR System 9600" (Perkin-Elmer). However, concentrations and total volumes were different. For a total volume of $25 \mu \mathrm{L}$, the following were used: $2.5 \mu \mathrm{L}$ PCR buffer10x; $1.5 \mathrm{mM} \mathrm{MgCl}_{2}$; $0.32 \mu \mathrm{M}$ forward primer; $0.32 \mu \mathrm{M}$ reverse primer; $5 \mu \mathrm{L}$ extraction solution; $0.2 \mu \mathrm{M}$ dNTP; 1 unit Taq DNA polymerase.

\section{Allele size determination}

Microsatellite alleles were separated in a $6 \%$ polyacrylamide gel on an A.L.F. sequencer (Pharmacia). Internal (IS) and external standards (ES) were used to accurately determine the size of the amplified products.

\section{Sample size determination}

The sample size representing the animals involved in the progeny test was calculated according to Barnett (1974):

$$
\mathrm{n} \geq \mathrm{N}\left\{1+\frac{1}{\mathrm{~N}}\left(\frac{\mathrm{D}}{\mathrm{ZS}}\right)^{2}\right\}^{-1}=\frac{\mathrm{N}}{1+\frac{1}{\mathrm{~N}}\left(\frac{\mathrm{D}}{\mathrm{ZS}}\right)^{2}}
$$

where $\mathrm{N}=$ total number of animals with production records used in the evaluation; $Z=1.96$ for $\alpha=0.95 ; S=$ square root of $\mathrm{N}$ (number of animals sampled) multiplied by $\mathrm{p}$ (percentage of paternity error found) multiplied by q (1-p); D = the difference between $p$ sampled to $p$ of population (error difference that can occur due to sampling for $\alpha=0.95$ ) and $\mathrm{p}=0.36$ (misidentification rate found).

\section{Exclusion probability (EP)}

The exclusion probability of a sire was calculated in relation to the progeny only, since in most cases there was no information on the dam. According to Ron et al. (1996):

$$
\mathrm{PE}=(1-\mathrm{pi})^{2}
$$

Table I - Description of six microsatellite primers and their respective annealing temperatures.

\begin{tabular}{llc}
\hline Microsatellite marker & Primer sequences 5' to 3' & Annealing temperature \\
\hline BM8246 & Forward AAT GAC AAA TTG AGG GAG ACG & $60{ }^{\circ} \mathrm{C}$ \\
Chromosome 1 & Reverse AGA GCC CAG TAT CAA TTC TTC C & \\
CSFM50 & Forward AGT TCT CCT CTT GAT TTC AGT AAC & $55^{\circ} \mathrm{C}$ \\
Chromosome 2 & Reverse CCT ACT TCC TGC CTT TGT AGC ATT & \\
BMS963 & Forward GGA GGA TGA AGG AGT CTT TGG & $58{ }^{\circ} \mathrm{C}$ \\
Chromosome 3 & Reverse AAT TTA CCA CAG TCC ACC GC & \\
TEXAN15 & Forward TCG CAA ACA GTC AGA GAC CAC TC \\
Chromosome 5 & Reverse TGG ATG AGA AAG AAG AGC AGA GTT G & \\
BMS483 & Forward GGT ATG AGA CCA GGT GTG GG \\
Chromosome 6 & Reverse CAG GGC CAC ATT TCC AAG & $56{ }^{\circ} \mathrm{C}$ \\
INRA112 & Forward GCC TCT CAA AGC CAC CTG C & \\
Chromosome 7 & Reverse GAT CTA ACT AGA GCT TTC C & $58{ }^{\circ} \mathrm{C}$ \\
\hline
\end{tabular}


where $\mathrm{pi}=$ sum of the frequencies of the two sire alleles.

Allele frequencies were determined from 64 not closely related Gir animals.

For multiple loci, the combined exclusion probability (CEP) was calculated according to Ron et al. (1996):

$$
\mathrm{CPE}=1-\prod_{\mathrm{m}}(1-\mathrm{PEi})
$$

where $\mathrm{m}=$ number of genotyped loci

$\mathrm{i}=\mathrm{i}^{\text {th }}$ marker $(1,2, \ldots, \mathrm{m})$

Exclusion was considered whenever the genotype of the bull was incompatible with the genotype of the mother-progeny pair with regard to at least one of the six markers.

\section{Genetic evaluation}

The MTDFREML system (Boldman et al., 1995) was used to evaluate the sires. The animal model used was: $\mathrm{Y}=\mu+$ animal + herd/year of calving + season of calving + genetic composition of daughter + age of cow at calving + error.

The initial records included all lactations of all daughters of all sires of all herds and the herd mates. Only the daughter's first lactation was taken into account. All lactations considered abnormal were excluded. Examples of abnormal factors are calf death or separation of calf from mother, disease, death or sale of a cow during lactation, teat loss due to mastitis, partial or total loss of lactation information, and intervals between test days greater than 75 days before completing 305 days of lactation.

To determine the impact of paternity error on the breeding program, the genetic values of the animals were compared before and after exclusion of the misidentified offspring from the analysis. Both results were compared by ordered correlation, using the Spearman method for 58 sires in the progeny test. This method evaluates the degree of association between the results of the two evaluations. The first one without corrections, and the second one after exclusion of the offspring records with incorrect paternity.

\section{Results and Discussion}

Information on allelic frequencies for several markers is available for many breeds. However, for Gir cattle, limited information has been published. Therefore, in order to calculate exclusion probabilities, we had to determine first the allelic frequencies of the microsatellites used in this study. The allelic frequencies of six microsatellites obtained from 64 unrelated individuals from several herds are presented in Table II.

The results obtained for both types of probability (exclusion and combined exclusion) according to Ron et al. (1996) are shown in Table III. Exclusion probability refers to the probability of excluding an incorrect paternity. For example, the probability of an incorrect paternity for sire 1 based on locus BM8246 only is 0.510203 , and the combined probability for the same sire using all six markers is 0.98 .

The combined exclusion probability (CEP) for the markers within the respective families varied from 0.842 to 0.989, which is less than the ideal 0.99. The CEP for seven markers with an EP of 0.5 would be 0.992 . A CEP of the same magnitude (0.991) could be reached with only four markers with an EP $=0.7$ (Rosa, 1997). Furthermore, according to Ron et al. (1996), if eight loci were genotyped with five alleles with the same 0.2 frequency for all loci, CEP would be 0.986 . Consequently, the power of exclusion will be maximized whenever the alleles of the probable sire are rare.

Microsatellite parentage testing revealed incompatible genotypes for at least one marker in 27 of the 74-bull/calf pairs studied (36\%). However, if only daughters which were incompatible with regard to at least two markers were excluded, 16 of the 74 animals analyzed would have incorrect paternity, and the misidentification rate would be $22 \%$.

Since we sampled only part of the animals in the progeny test, we used Barnett's equation to determine if our sample size was sufficient to represent the population. According to our calculations, the use of a sample of 74 animals and a misidentification rate of $36 \%$ resulted in a type I error of 0.051 , which was adequate for our study.

The $36 \%$ misidentification rate is higher than those found by Geldermann et al. (1986), Ron et al. (1996), and Rosa (1997), which varied between $4 \%$ and $23 \%$. This observation indicates that more accurate procedures to identify the animals are necessary. Alexander et al. (1983) suggested that, for information on cattle breeding to be considered accurate, data need to be based on a variety of factors, such as secure animal containment, visual control of mounting or artificial insemination, and observation of parturition or suckling activity.

It is interesting to note that, of the 27 daughters considered to have incorrect paternity, eight had already been excluded by the data verification procedures already in place in the progeny test. Thus, the criteria used to decide whether or not lactation should be considered are justified for the detection of incorrect or dubious data.

An important factor contributing to misidentification is incorrect identification of the semen used in the receptor cows. We assumed that animals which did not get pregnant upon the first insemination and were re-inseminated would be more likely to have an incorrect record. Our data, however, did not show any relationship between the number of inseminations and progeny misidentification. An identical number of wrong paternities was observed for animals resulting from first and from second inseminations.

In our study, exclusion of paternity was based on at least one marker. In human paternity studies, at least two markers are required for exclusion. This is important, be- 
Table II - Allele frequencies of microsatellites.

\begin{tabular}{|c|c|c|c|c|c|}
\hline \multicolumn{2}{|c|}{ BM8246 } & \multicolumn{2}{|c|}{ BMS963 } & \multicolumn{2}{|c|}{ TEXAN15 } \\
\hline Allele & Frequency & Allele & Frequency & Allele & Frequency \\
\hline 171 & 0.015873 & 134 & 0.016129 & 201 & 0.301587 \\
\hline 175 & 0.134921 & 136 & 0.419355 & 203 & 0.166667 \\
\hline 177 & 0.023810 & 138 & 0.040323 & 205 & 0.214286 \\
\hline 179 & 0.230159 & 140 & 0.008065 & 207 & 0.111111 \\
\hline 181 & 0.015873 & 144 & 0.008065 & 209 & 0.047619 \\
\hline 183 & 0.015873 & 146 & 0.153226 & 215 & 0.007937 \\
\hline 187 & 0.039683 & 148 & 0.024194 & 217 & 0.007937 \\
\hline 189 & 0.007937 & 150 & 0.161290 & 219 & 0.087302 \\
\hline 191 & 0.031746 & 152 & 0.008065 & 221 & 0.055556 \\
\hline 193 & 0.039683 & 154 & 0.032258 & & \\
\hline 195 & 0.373016 & 156 & 0.112903 & & \\
\hline 197 & 0.055556 & 158 & 0.016129 & & \\
\hline 199 & 0.015873 & & & & \\
\hline \multicolumn{2}{|c|}{ BMS483 } & \multicolumn{2}{|c|}{ CSFM50 } & \multicolumn{2}{|c|}{ INRA112 } \\
\hline Allele & Frequency & Allele & Frequency & Allele & Frequency \\
\hline 105 & 0.015873 & 174 & 0.008197 & 188 & 0.008065 \\
\hline 107 & 0.230159 & 170 & 0.245902 & 190 & 0.008065 \\
\hline 109 & 0.460317 & 176 & 0.196721 & 186 & 0.048387 \\
\hline 111 & 0.031746 & 178 & 0.106557 & 164 & 0.032258 \\
\hline 113 & 0.095238 & 172 & 0.057377 & 184 & 0.040323 \\
\hline 115 & 0.158730 & 168 & 0.368852 & 172 & 0.112903 \\
\hline \multirow[t]{7}{*}{117} & 0.007937 & 180 & 0.016393 & 182 & 0.104839 \\
\hline & & & & 178 & 0.064516 \\
\hline & & & & 168 & 0.088710 \\
\hline & & & & 170 & 0.129032 \\
\hline & & & & 174 & 0.072581 \\
\hline & & & & 180 & 0.169355 \\
\hline & & & & 166 & 0.120968 \\
\hline
\end{tabular}

Table III - Exclusion probability (EP) and combined exclusion probability (CEP) for nine bulls and six microsatellite markers.

\begin{tabular}{lccccccc}
\hline \multirow{2}{*}{ Sire } & \multicolumn{5}{c}{ PE } & \multirow{2}{*}{ CEP } \\
\cline { 2 - 6 } & BM8246 & BMS963 & TEXAN15 & BMS483 & CSFM50 & INRA112 & \\
\hline 1 & 0.51 & 0.76 & 0.52 & 0.10 & 0.26 & 0.59 & 0.98 \\
2 & 0.16 & 0.18 & 0.44 & 0.01 & 0.15 & 0.59 & 0.87 \\
3 & 0.06 & 0.85 & 0.44 & 0.47 & 0.15 & 0.55 & 0.98 \\
4 & 0.37 & 0.91 & 0.48 & 0.10 & 0.07 & 0.61 & 0.99 \\
5 & 0.53 & 0.92 & 0.16 & 0.01 & 0.19 & 0.49 & 0.99 \\
6 & 0.29 & 0.31 & 0.23 & 0.01 & 0.15 & 0.50 & 0.84 \\
7 & 0.53 & 0.30 & 0.34 & 0.01 & 0.56 & 0.59 & 0.96 \\
8 & 0.37 & 0.03 & 0.23 & 0.88 & 0.42 & 0.44 & 0.98 \\
9 & 0.53 & 0.54 & 0.16 & 0.01 & 0.56 & 0.68 & 0.97 \\
\hline
\end{tabular}


Table IV - The genetic values of sires altered after the second evaluation.

\begin{tabular}{lcccc}
\hline Sire & GV.ERR* & CONF.ERR** & GV.COR *** & CONF.COR**** \\
\hline 1 & -47.682 & 0.78 & -36.603 & 0.77 \\
2 & 417.226 & 0.82 & 440.216 & 0.81 \\
3 & -83.188 & 0.87 & -60.883 & 0.87 \\
4 & 245.003 & 0.83 & 250.864 & 0.83 \\
5 & 491.211 & 0.75 & 511.050 & 0.74 \\
6 & 73.796 & 0.88 & 80.266 & 0.87 \\
7 & 291.615 & 0.77 & 235.406 & 0.76 \\
8 & 595.625 & 0.80 & 577.796 & 0.80 \\
9 & -43.740 & 0.72 & -0.145 & 0.71 \\
\hline
\end{tabular}

*GV.ERR genetic value on the first evaluation.

**CONF.ERR reliability on the first evaluation.

***GV.COR genetic value on the second evaluation.

$* * * *$ CONF.COR reliability on the second evaluation.

cause a mutation may generate a new allele in the offspring, wrongly suggesting exclusion of paternity (Halos et al., 1999). However, since the mutation rate in microsatellites is relatively small, it would have a minimal impact on our study.

In order to investigate the effect of misidentification on the estimation of breeding value in Gir cattle, the genetic values of the sires were compared before and after the exclusion of the animals which were not daughters of the indicated bull. The resulting correlation of order by the Spearman method using the SAS system was 0.997, showing that the difference found in bull classification before and after the correction was not significant.

As can be seen by the results, the genetic value of some sires was altered after the second evaluation (Table IV). The effect, however, was small and had a minimal influence on the ranking of the sires. It was interesting to observe that some sires which were not tested for paternity had their genetic values changed (data not shown). This could be due to some relationship that might exist among them, or, in other words, other daughter companions to the herd which could influence the evaluation of a given sire. In conclusion, our study clearly demonstrates that there is a need to conduct paternity evaluation in progeny test programs to assure accuracy of the genetic values of the sires.

\section{Acknowledgments}

This research was funded by Fundação de Amparo à Pesquisa do Estado de São Paulo (FAPESP) and by Empresa Brasileira de Pesquisa Agropecuária - Embrapa Gado de Leite. The authors thank FAPESP for financing this study. E.E.Baron is recipient of a scholarship from FAPESP. L.L.Coutinho, M.L.Martinez and R.S.Verneque are recipients of scholarships from CNPq (Conselho Nacional de Desenvolvimento Científico e Tecnológico).

\section{References}

Alexander G, Stevens D and Mottershead B (1983) Problems in the accurate recording of lambing data. Aust J Exp Agric Anim Husb 23:361-368.

Barendse W, Armitage SM, Kossarek LM, Shalom A, Kirkpatrick BW, Ryan AM, Clayton D, Li L, Neibergs HL, Zhang N, Grosse WM, Weiss J, Creighton P, McCarthy F, Ron M, Teale AJ, Fries R, McGraw RA, Moore SS, Georges M, Soller M, Womack JE and Hetzel DJS (1994) A genetic linkage map of the bovine genome. Nat Genet 6:227-235.

Barnett V (1974) Elements of sampling theory. London: English University Press, 151p.

Boldman KG (1995) A Manual for use of MTDFREML: A set of programs to obtain estimates of variances and covariances. Lincoln, USDA, 120 pp.

Burns BM, Taylor JF, Herring KL, Herring AD, Holder MT, Collins JS, Guerra TM, Sanders JO and Davis SK (1995) Bovine microsatellite dinucleotide repeat polymorphisms at the TEXAN11, TEXAN12, TEXAN13, TEXAN14 and TEXAN15 loci. Anim. Genet. 26:201-213

Geldermann H, Pieper U and Weber WE (1986) Effect of misidentification on the estimation of breeding value and heritability in cattle. J of Anim Sci 63:1759-1768.

Glowatzki-Mullis M-L, Gaillard C, Wigger G and Fries R (1995) Microsatellite-based parentage control in cattle. Anim Genet 26:7-12.

Halos SC, Chu JY, Ferreon ACM and Magno MMF (1999) Philippine population database at nine microsatellite loci for forensic and paternity applications. Forensic Sci Int 101:27-32.

Heyen DW, Beever JE, Da Y, Evert RE, Green C, Bates SRE, Ziegle JS and Lewin HA (1997) Exclusion probabilities of 22 bovine microsatellite markers in fluorescent multiplexes for semiautomated parentage testing. Anim Genet 28:21-27.

Kappes SM, Keele JW, Stone RT, McGraw RA, Sonstegard TS, Smith TPL, Lopez-Corrales NL and Beatie CW (1997) A second generation linkage map of the bovine genome. Genome Res 7:235-249. 
Moore SS, Byrne K, Berger KT, Barendse W, McCarthy F, Womack JE and Hetzel DJS (1994) Characterization of 65 microsatellites. Mamm Genome 5:84-90.

Ron M, Blanc Y, Band M, Ezra E and Weller JI (1996) Misidentification rate in the Israeli dairy cattle population and its implications for genetic improvement. J Dairy Sci 79:676-681.

Rosa AJM (1997) Caracterização da raça Nelore e teste de paternidade por marcadores moleculares. Piracicaba, p.125. Master's Thesis - Escola Superior de Agricultura "Luiz de Queiroz", Universidade de São Paulo.

Shuster DE, Kehrli MEJr, Ackermann MR and Gilbert RO (1992) Identification and prevalence of a genetic defect that causes leukocyte adhesion deficiency in Holstein cattle. Proc Natl Acad Sci 89:9225-9229.
Stone RT, Pulido JC, Duyk GM, Kappes SM, Keele JW and Beatie CW (1995) A small-insert bovine genomic library highly enriched for microsatellite. Mamm Genome 6:714.

Usha AP, Simpson SP and Williams JL (1995) Probability of random sire exclusion using microsatellite markers for parentage verification. Anim Genet 26:155-161.

Vaiman D, Mercier D, Moazami-Goudarzi K, Eggen A, Ciampolini R, Lepingle A, Velmala R, Kaukinen J, Varvio SL, Martin P, Levéziel H and Guérin G (1994) A set of 99 cattle microsatellite: characterization, synteny mapping and polymorphism. Mamm Genome 5:288-297.

Via LE, Jr and Stewart CN (1993) A rapid CTAB DNA isolation technique useful for RAPD fingerprinting and other PCR applications. BioTechniques 14:748-751.

Walsh PS, Metzger DA and Higushi R (1991) Chelex 100 as a medium for simple extraction of DNA for PCR-based typing from forensic material. BioTechniques 10:506-513. 